\title{
EL MUNICIPIO DE MADRID Y SU AYUNTAMIENTO
}

\section{PARQUES Y JARDINES}

El Servicio de Parques y Jardines es seguramente uno de los servicios municipales que más han sufrido con la guerra. Por una parte, a causa de los daños ocasionados en los Parques del Deste, de la Dehesa de la Villa, de la Moncloa y en la Casa de Campo, que durante mucho tiempo han sido campos de la lucha, y por otra, por el forzado descuido de parte de los jardines situados en el casco de la población, debido a falta de personal, pues los obreros fueron dedicados, unos, a otros trabajns considerados por el Municipio como más urgentes, y otros, les más jóvenes, incorporados a filas en gran número.

Unanse a los daños anteriormente señalados los perjuicios ocasionados en el arbolado de las calles, plazas y paseos, por el público, que, falto de combustible, no encontraba otro medio de proporcionárselo, para remediar su angustiosa situación, que cortar el arbolado que encontraba a su mano.

Especial mención merece en esta información el Parnute de Madrid, el Retiro, que a duras penas y tras largos esfucizos la Jefatura del Servicio consiguió salvar de las constantes amenazas de su tala y de los destrozos que ocasionara en el mismo la ocu. pación que de él hacían fuerzas militares no bien disciplinaras.

Fn el invierno de 1937, principalmente, la lucha que la Jefatura tuvo que sostener en defensa del arbolado del Retirn fué enorme, sin que por ello pudiera evitar la tala de más de 3.000 árboles y la poda a fondo de los que se respetaban: Posterinrmente, una mayor organización de la vida en Madrid, permitió evitar continuase la tala de árboles en los Parques, sin lograr impedir la excesiva poda del arbolado de las calles que llevó a cabo ha Junta de Defensa.

:760 Es preciso señalar también las medidas que la Jefantura del 
Servicio tuvo que tomar en noviembre del 36 , cuando pri orden de la autoridad militar fueron una noche guardadas en el Parque de Madrid más de 20.000 cabezas de ganado merino y 2.0.00 cabras, que hicieron, principalmente estas últimas, en los primeros momentos, grandes destrozos en el arbustaje, hasta que rápidamente se tomaron las precauciones pertinentes, en evitación de mayores daños, y debido a las cuales todavía existen la Rosalèda, el Parterre y los jardines de la prolongación de la Casa de Fieras.

Constantemente, la Jefatura de Servicios llamó la atención de la Alcaldia Presidencia acerca de la importancia y del interés extraordinario que para Madrid tenía la conservación de sus superficies verdes, de sus jardines y arbolado, ya que se trata de elementos esenciales a la vida de la ciudad y cuya reposición no es sólo cuestión de dinero, sino de muchos años de incesantes esfuerzos.

La circunstancia de quedar en la zona de guerra una gran parte de los Parques, jardines y arbolado de calles, así como todos los viveros, dificultó a la Jefatura del Servicio su defensa y conservación; sin embargo, en repetidas ocasiones se dirigió a las autoridades militares, denunciando casos de destrucción sistemática de arbolado que no se juzgaban necesarios a los fines militares y sí sólo fruto de desorganización o de iniciativas esporádicas por parte de oficiales poco comprensivos y menos amigos del árbol.

Ejemplo de lo que anteriormente decimos fueron las repetidas reclamaciones hechas por corta de árboles en el reservado de la Casa de Campo y en el ingreso principal de la misma, en la Cuesta de la Vega, en la Plaza de Oriente, en el Cementerio de San Martín, en la calle de la Princesa, etc.

Señalando el detalle de la gestión de la Jefatura del Servicio a lo largo del tiempo que la guerra ha durado, debemos consignar también, que durante muchos meses-a partir del comienzo del Movimiento-la existencia de un Comité de control en el Servicio dificultó extraordinariamente su gestión, hasta el extremo de anularla por completo, como ocurrió en todos los Servicios municipales; época de larga duración, durante la cual los jefes desempeñaron un papel muy secundario, pues en realidad la Jefatura de los Servicios estaba en manos de los designates por las Sindicales en los mencionados Comités de control. 
Afortunadamente para los intereses del Ayuntamientı, aquella época pasó y se pudo de nuevo ejercer la función directora, poniendo en ella el acostumbrado celo en defensa de los intereses de la ciudad.

Otro grave mal que en el momento de iniciarse la obra de reconstrucción se ofrecía al Ayuntamiento era la falta del funcionario que durante muchos años fué alma del Servicio de Parques y Jardines y autor en un período de casi medio siglo de todas las obras de este carácter existentes hasta el año 1936.

Atendiendo a los ruegos de la Alcaldía y llevado de su afecto a Madrid y ai Servicio, este funciondrio, jubilado ya, reingresó de nuevo en su antiguo cargo, en el cual, y/ desde la fecha de la. liberación, ha llevado a efecto obras tan importantes comn la limpieza de la Casa de Campo y del Parque del Oeste, librándoles del peligro que representa la existencia de material de guerra y municiones, diseminados y enterrados en dichas fincas, procediendo a un nuevo replanteo de este último parque.

Al propio tiempo han sido reparados todos los daños ocasionados en el Retiro y en los demás jardines públicos, realizándose en aquél importantes obras de embellecimiento.

En general, han resurgido desde la liberación de Madrid los. siguientes jardines: Isabel II, Santo Domingo, Plaza de Espana, Ferraz, Princesa, Cristino Martos, Quevedo, Chamberí, Avenida de Calvo Sotelo, Avenida del Generalísimo, Neptuno, Encarnación, Salesas, Museo de Pinturas, Villa de París, Salamanca, Manuel Becerra, Sánchez Bustillo, Jardines de la Tela (Cuesta de la Vega) Bilbao, Tirso de Molina, Cortes y Joaquín Dicenta.

Asimlsmo, en este plazo se han ejecutado las siguientes obras:

Casa de Campo.-Reconstrucción de las tapias de cerramiento. Tapado de trincheras. Limpieza de material bélico. Fspaciosa tala de árboles secos. Reposición de arbolado en todos sus paseos y avenidas.

Viveros de la Villa (Puerta de Hierro).-Resurgimiento de los viveros en toda su extensión, desde el Puente de los Franceses hasta Puerta de Hierro. Tapado de trincheras. Niveln:ión de terrenos. Plantación de viveros de 287.350 árboles de distintas variedades.

Viveros del Puente de Toledo y Sotillo.-Rehabilitación de todos estos terrenos.

762 Parque de Madrid.-Nuevo trazado del Paseo de Coches. 
Reforma de entrada de las Puertas de la Independencia y Herna-ni. Reforma de la Plaza de Martínez Campos y fuente de már-mol. Rehabilitación de la Rosaleda, con plantación de rosales de diversas especies, en número de 8.000. Obras de ampliación del Parque Zoológico.

Parque del Oeste.-Reconstrucción total. Plantación de árboles de distintas especies, arbustos, coníferas, etc. Reposición. total de la canalización desde el Cementerio de San Martín hasta el centro del Parque, con tuberías de hierro. Instalación de tuberias de plomo y gran número de bocas de riego.

Por último, entre las iniciadas, deben hacerse constar las siguientes: Formación de los jardines de la Plaza de Oriente y antiguas Caballerizas Reales. Continuación de las obras de ampliación del Parque Zoológico y Parque del Oeste.

Importante es asimismo consignar las plantaciones de arbo-. lado llevadas a efecto, según el siguiente detalle:

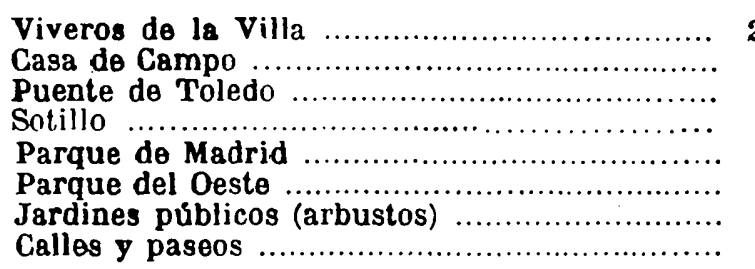

$\begin{array}{rc}287.350 & \text { árboles } \\ 6.000 & = \\ 15.900 & " \\ 17.094 & " \\ 12.300 & " \\ 6.000 & " \\ 3.700 & " \\ 18.000 & "\end{array}$

El gasto de este servicio, según el último presupuesto ordi-nario de 1943, representa las siguientes cifras:

$$
\begin{aligned}
& \text { 3.011.ror pesetas en jornales } \\
& \text { 180.000 " en materiales }
\end{aligned}
$$

Con cargo al presupuesto extraordinario, las siguientes cantidades:

$$
\begin{aligned}
& 2.396 .200,76 \text { pesetas en jornales } \\
& 250.000,00 \text { " } " \text { in materiales }
\end{aligned}
$$

Ingresos por venta de billetes de entrada al Parque Zoológico durante el año I943: I96,836 pesetas.

Los Parques y Jardines componen una superficie de 18.152 .585 metros cuadrados, que, unidos a los 143.178 de los jardines de la población, hacen un total de 18.295 .763 metros cuadrados, lo que representa un porcentaje de un 27,40 por roo en relación con el núcleo urbano. 


\section{OBRAS SA N T A R I A S}

Las líneas generales de los cometidos de los Servicios dependientes de esta Dirección, así como su estado actual y proyectos de obras o reorganización a realizar son los siguientes:

Servicios de Limpiezas.-El Servicio de Limpiezas está en plena evolución, inciada en 1930 y retrasada y dificultada por la pasada guerra y las repercusiones de la actual en el material e instalaciones que para conseguir el pleno desarrollo precisa.

Está dividido el Servicio en cinco Zonas, con un total de obreros de unos 1.300 hombres, que tienen a su cargo el barrido, riego y servicio de repaso permanente en las vías públicas. con carácter estrictamente municipal.

De los tres aspectos de este Servicio, a saber, barrido y riego viario, recogida de basuras y tratamiento de las mismas, solamente el primero, como se ha dicho, es municipal.

Los otros dos se explotan por empresas concesionarias, fisralizadas técnicamente por el Servicio Municipal.

La recogida de basuras comenzó a funcionar con carácter de empresa en octubre de 1940, previo concurso público.

El plan establecido era de que en un plazo de dos años se fuese a la transformación total del material mecánico de recogida. a la adopción de cubos de tipo determinado para la debida higienización de esta recogida y para suprimir en absoluto lrs traperos, que en número de unos 900 subsisten aún en Madrid, ejerciendo su modesta industria en condiciones sumamente tesfavorables desde el punto de vista sanitario.

Desgraciadamente, la imposibilidad de adquisición de materia! de ninguna clase, y sobre todo, la restricción severísima en cuanto a gasolina, neumáticos y demás elementos de tracción mecánica, que se ha producido, obligan a aplazar "sine -die" el comienzo de este periodo provisional de transformación de material y a prestar el servicio con los elementos de que puede disponerse.

Aun así, el tonelaje medio de basuras recogidas diariamente ha llegado a alcanzar cifras de 240 toneladas, oscilando entre dicha cifra y la de 170, según los días y las estaciones.

No obstante, la recogida total está prevista para un tonelaje medio de 400 toneladas diarias, al ser suprimidos los traperos.

Dada la escasez normal de medios mecánicos, rayana casi en 
la carencia, pues no ha quedado utilizable ni una sola barredera mecánica, y prestan servicio tres o cuatro regadoras nada más, dada la conveniencia de unificar los tres aspectos del Servicio, el Ayuntamiento tiene aún por resolver la cuestión de si, el Ser.vicio de Limpieza y riego varios, va a seguirse haciendo con carácter estrictamente municipal, invirtiendo las sumas precisas para la dotación de medios mecánicos, el día que esto sea posible, o va a organizarlo en régimen de empresa intervenida, con arreglo a unas bases de estudio.

El Servicio dispone hoy día de cuatro Parques de personal y pequeño material y varios Cantones o Parques destacados, de barrio. Los primeros son: los de Santa Engracia, Jorge Juan. Costanilla de los Desamparados y Cebada.

$\mathrm{Y}$ los segundos existen en las calles de Palencia, Santa Cruz de Marcenado, López de Hoyos, Puente de Toledo y Puente de Segovia; pero todos ellos con instalaciones elementales de albergue de carrillos, palas, cepillos y escobijos, que, en caso de continuar el servicio con carácter municipal, habrían de sufrir honda transformación.

El material de barriạo se modernizó en I934 a base te cepillos y escobijos de piazzaba fabricados por el propio personai, constituido en Cooperativa, con resultados francamente favorables para la economía del Ayuntamiento y de los interesarlos.

Los cogedores son de tipo moderno, original, construídos igualmente.

Los carrillos de recogida se han modificado buscando el mínimo peso e igualdad de rendimiento.

Las palas de recogida son asimismo de tipo especial.

El servicio de riego está hoy confiado casi exclusivamente a las mangas, y gracias a la práctica del personal que las maneja, es hoy Madrid una de las poblaciones mejor atendidas en este aspecto, habida cuenta de la sequedad del clima y circunstancias estimulantes del polvo.

\section{A G U A S}

Abastecimientc de aguas.-Epoca antigua.-Pocos datos tenemos del suministro de agua en Madrid en épocas anterinres al establecimiento de la Corte. Lo más probable es que se hiciera como en la mayoría de las pequeñas poblaciones de entonces, o sea, 765 
sirviéndose de las aguas del río y de algunos manantiales de los: alrededores.

En el archivo municipal hemos encontrado datos de la llamada Fuente de las Damas, posteriormente Fuente de la Reina, y del viaje de la Alcubilla en los siglos XIII, XIV y XV. De estas. fuentes, $y$ por medio de aguadores, se distribuia por la pequeña. ciudad que entonces era nuestra capital.

Una vez establecida definitivamente la Corte en Maclrid, es. a fines del siglo XVI y principios del XVII cuando el problema del agua se agudiza en nuestra villa, pues con el aumento lógico de población, debido a su transformación en capital de España, ya no bastaron los pequeños manantiales de las afueras, y, sobre todo, la falta de medios de transporte para el agua-que, aunque entonces se tenía otro concepto más primitivo del asen y de las actuales costumbres higiénicas constituía casi un pecadohizo que los gobernantes buscaran soluciones al problema.

De esta época data la construcción de la mayoría de los antiguos viajes de agua que constan en esencia de unas arquetas y galerías filtrantes de captación y unas galerías de transpirte en las cuales el agua va unas veces rodada y otras entubada hasta las fuentes distribuidoras en el interior de la ciudad. Por este procedimiento se hacían llegar a Madrid unos 3.000 metros cúbicos diarios, que abastecían unas fuentes públicas y algunas concesiones a edificios oficiales, conventos y particulares, constituyendo con los pozos el total abastecimiento de la capital.

De estos antiguos viajes algunos se hallan completamenteperdidos, como son los de San Dámaso, Pajaritos, Retiro. Condede Salinas y Retamar; otros son de propiedad particular, como el de Amaniel, que pertenece al Patrimonio, y el de la Fuente del Berro, propiedad particular.

Vamos, pues, a describir únicamente los que de propiedad: municipal prestan en la actualidad algún servicio.

Alcubilla.-Las primeras noticias que tenemos sobre su construcción datan del año 1399, y quizá sea el primer intento de abastecimiento de la capital. Posteriormente, a fines del siglo XVI, fué ampliado y reformado; nace en el término de Fuencarral, terrenos de Don Pedro, frente a la finca de los Tres Hermanos, al poniente de la carretera de Francia; cruza el camino del Sotillo y los terrenos de Fuente Moreno y llega a la casilla de la Alber$766 \mathrm{ca}$, en donde empieza a ir entubado en tuberías de 70 milímetros; 
atraviesa Tetuán de las Victorias por las calles Cristino, Carmen, Rosario Romero, Antonio Maria Quijano hasta María Zayas, en donde empieza la conducción de agua para Madrid, vertiendo en la estación ozonizadora de la glorieta de la Iglesia, de donde parten dos minas: una, que va por Santa Engracia y Luchana, y la otra, por Eloy Gonzalo, glorieta de Quevedo, San Bernardo hasta la glorieta de San Bernardo. De aqui parten varios ramales: uno, a la glorieta de Bilbao, Fuencarral, San Iliefonso, Corredera de San Pablo, Escorial y Madera; otro baja por San Bernardo, San Hermenegildo, Acuerdo y Montserrat y sigue en tuberia enterrada hasta Conde Duque; otro ramal ha ja por Alberto Aguilera, Princesa y llega hasta la antigua Cárcel Modelo.

Los principales ramales afluentes de este viaje son los siguientes: de los Marqueses, del Monte, de los Olivos, de la Cruz, de los Formos, Erales, San Isidro, San Joaquín, San Juan Bautista, San Pedro Alcántara, Dehesa Quemada, Santiago, los Pinos. Cambrija y Ardemáns.

La longitud total del viaje de Alcubilla es de 21.726 metros. Alto Abroñigal-Se construyó en I6I4. Nace en el término de Canillas, al norte de la carretera de Magán, en el lıgar denominado los Mochuelillos, cruza la llamada Huerta de los Gascones y las calles de Francisco Santos, Pilar de Zaragoza, Cartagena, Ardemáns, Francisco Silvela, Alcántara, Torrijos, Hermanos Miralles, Lista, Don Ramón de la Cruz, General Mola, Castelló, Núñez de Balboa, Velázquez, Lagasca, Claudio Coello, Serrano y llega a Castellana esquina a Villamagna; baja hasta Ayala por Fernando el Santo, Almagro, Alonso Martínez y vierte a la Plaza de Santa Bárbara.

A la salida de la estación ozonizadora baja por Hortaleza, Aduana, Alcalá, Nicolás María Rivero, Ventura de la Vega, Antón Martín y Magdalena, en donde termina.

Los ramales principales que afluyen a este viaje son: Pepe Lahermosa, Llanos, del Moreno, La Junquera, Retamar y Bastiones.

Bajo Abroñigal.-Se construyó en i619. La confluencia de los ramales que lo alimentan coincide con la casilla de los Mochuelos; entra en Madrid por la calle de Francisco Cernuda, Francisco Silvela, Avenida del Conde de Peñalver esquina a 767 
Lista, Hermanos Miralles y General Mola y vierte en la estación ozonizadora de Goya, esquina a Serrano.

Sale del ozono por Serrano, Independencia, Alcalá, Cibeles, Paseo del Prado, Dos de Mayo y Botánico. De Cibeles.sale un ramal, que sube por Alcalá, Sevilla, calle de la Cruz, Concepción Jerónima, Conde de Romanones y Duque de Rivas, con ramales desde Puerta Cerrada al Puente de Segovia y de Progreso a Embajadores y Cascorro.

I.os principales ramales afluentes son: del Calero, de ln Perejilera, Calanera, Escalerilla, Retamar y Boticaria.

$\mathrm{Su}$ longitud total es de 23.907 metros.

Vialje de la Avenida del Generalísimo.-Se construyó el año r62 I. Nace en Chamartín de la Rosa, en las proximidades de la ralle Mateo Inurria; pasa frente al Hotel del Negro, sigue por la carretera de Maudes, barrio de los Angeles, Paseo de Ronda, Nuevos Ministerios, calle de Bretón de los Herreros, Zurbano, Abarcos. Miguel Angel, Almagro y vierte al ozono de Santa Bírbara.

De aquí salen dos ramales pequeños; uno a la Plaza de las Salesas y otro a Colón. Sale una tubería que va por Hortaleza, Peligros, Sevilla, a las Plazas de Santa Ana y del Angel, con diferentes ramales a San Marcos, Cruz, etc.

Sus ramales afluentes son: del Portazgo, de Maudes, de Pío Pío, de Miranda, del Arroyo, de la Viña, del Lagarto, de Ardemans, y travesía de la Avenida del Generalísimo.

$V$ iaje de Fuente La Reina.-Denominado al principio Fuente de las Damas, se encuentra enclavado en las inmediaciones de El Pardo y no se pensó en aprovechar sus aguas para la capital hasta 1850 , en que el aumento de población (entonces de unos 200.000 habitantes) exigía un caudal mayor de aguas. estando ya en proyecto los Canales de Isabel II.

Se construyó una mina hasta el pie de la Montaña del Príncipe Pío, y desde allí, por medio de una elevadora, se lleva a diferentes fuentes.

El proyecto fué estudiado por los Ingenieros de Caminos don Calixto Santa Cruz y don José Echegaray y ejecutado en ro meses por el Ingeniero del mismo Cuerpo don Rafael López, siendo Alcalde de Madrid el Excmo. Sr. don Valentín Ferraz.

Como resumen de esta obra, se escribió un folleto que ha llegado a nuestras manos, editado en la Imprenta, fundición y libre768 ría de don Eusebio Aguado, en el año $185^{6}$, en el que aparecen 
reflejados con todo detalle los trabajos e incluso curiosas disputas profesionales, que por lo visto siempre hubo en todo tiempo.

Estado actual de los viajes.-En general, se encuentran todos en regular estado de conservación, y salvo algunos que se hallan cortados circunstancialmente por obras ajenas al Municipio, como son Metropolitano y Enlaces Ferrcviarios, se encuentran prestando servicio.

En estos tres años largos que han seguido a nuestra guerra, hemos atendido a las pequeñas obras de conservación, tales como hundimientos, averías y otras análogas, pero sin modificar en esencia la estructura de los viajes y sin acometer obras nuevas.

Toda la labor realizada se ha llevado a cabo con el jersonal del Servicio, y, por lo tanto, con gran economía para e! Municipio. En el porvenir se ha de pensar en, por lo menos, conservar y mantener estas obras que aportan a la capital un caudal je 3.000 metros cúbicos diarios, no del todo despreciable.

Necio sería pensar que con él vamos a resolver problemas de importancia, pero tampoco es aconsejable abandonar ohra ya hecha y que con poco costo puede conservarse.

Podrían acometerse obras de acondicionamiento de gailerías y reforma y ampliación de las ozonizadoras, y otras que permitan utilizar el caudal para fuentes públicas y servicios municipales, romo por ejemplo, Piscinas, de las que tan falto está nuestro Municipio.

Recientemente y con motivo de la guerra estuvieron a punto de ocurrir sucesos por los cuales Madrid no hubiera contado para su suministro con más agua que la de estos antiguos viaje.s, v aun. que es de esperar que estas circunstancias no se repitan nunca, no sería económico ni prudente despreciar este pequeñr caudal de aguas.

Canales de Isabel II.-El abastecimiento de agua de Madrid está constituído por el organismo del Estado denominado Canales de Isabel II, con total independencia del Municipio.

Mediado el siglo XIX Madrid, con sus 200.000 habitantes, comenzó a cobrar rango de gran ciudad, y se hizo imprescindible, por tanto, atender a sus servicios de una manera decorosa. Uno de los menos atendidos era el abastecimiento de aguas, cuya escasez planteaba grandes problemas y para resolverlos, el ro de mayo de I848, Bravo Murillo, Ministro de Obras Públicas, comisionó a los Ingenieros de Caminos señores Rafo y Rivera para 769 
que informasen sobre la media docena de estudios y proyectos que desde mitad del siglo anterior venian of reciéndose para abastecer a Madrid con aguas de los ríos más inmediatos. Al cabo de nueve meses, dichos Ingenieros entregaron una Memoria (que fué aprobada), en la cual se proponía el abastecimiento de $\mathrm{Ma}$ drid con un canal de Lozoya.

Después de diferentes gestiones, el 18 de julio de I85I, Bravo Murillo, entonces Presidente del Consejo de Ministros, refrendó el Real Decreto, por el cual, el Gobierno se encargaba de realizar el proyecto, y acto seguido comenzaron las obras. Estas consisten en esencia en una serie de embalses (Fuentes Viejas, Pontón de la Oliva, etc.), de los cuales arranca un canal de 77 kilómetros de longitud, con 36 túneles, cuya longitud integrada es de I I,7 kilómetros y con una capacidad de transporte de 2,7 metros cúbicos por segundo; vertiendo estas aguas en tres depósitos construidos en las calles de Bravo Murillo y Santa Engracia.

Posteriormente se ha construido otro segundo canal de 55 kilómetros de longitud y una capacidad de 6 metros cúbicos por segundo; y un cuarto depósito situado en las proximidacies del Hotel del Negro, y en comunicación con los otros tres.

En la actualidad se hallan en construcción otros dos tepósitos, uno en el término de Canillas y otro en Cerro Palomera, en las proximidades de Vallecas. Estos dos depósitos irán enlazados con el cuarto por medio del canal del Este, también en construcción.

No nos detenemos en descripciones minuciosas, por ser organización de sobra conocida y únicamente citaremos algunos datos estadisticos.

Presa del Villar: Altura, 35,55 metros; capacidad, 22 millones de metros cúbicos.

Presa de Fuentes Viejas: Altura, 59,55 metros; capacidad. 52 millones de metros cúbicos.

Los depósitos, tanto en servicio como en construcción, son los que corresponden al siguiente diseño: 


\section{Depósitos del Canal de Isabel II}

COTAS ALTIXETRICAS

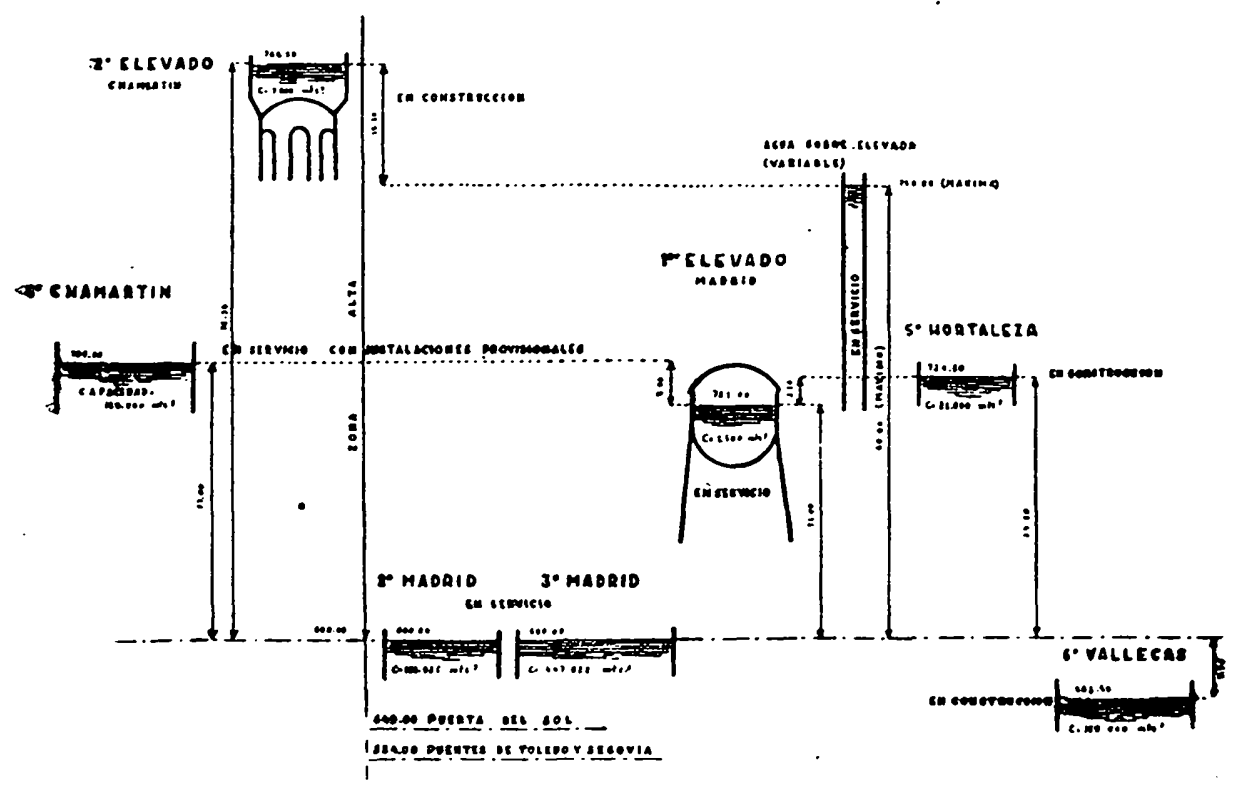

I.a red de distribución comprende 3.500 metros de acequias y unos 300.000 metros de tubería, propiedad de Canales, I20.000 de servicios municipales y unos 86.000 de particulares.

El agua de Canales de Isabel II, es de una calidad casi inmejorable, disfrutando actualmente la Capital, de unos 30u litros por habitante y día, y una vez que se terminen las obras del quinto y sexto depósitos, podremos contar con más de 500 litros por habitante y día.

Actualmente figura Madrid entre las 20 mejores capitales del mundo por su abastecimiento de aguas; y cuando terminen las obras en construcción, será la primera ciudad de Europa y.de las 10 primeras del mundo.

Respecto a Tarifas hemos de decir que el agua es en nuestra rapital, extraordinariamente barata, pues no conocemos ninguna otra ciudad del mundo en que el metro cúbico alcance tan bajo precio. Este es de o,30 céntimos como máximo, pudiendo ser de 0,20, 0,10, ó 0,05 el metro cúbico, según la cantidad consumida y el uso que se haga de ella.

El Municipio tiene el privilegio de agua completamente gratuita. 
Esta Entidad suministra anualmente a Madrid unos $250 \mathrm{mi}$ llones de metros cúbicos.

Sodiedad Hidráulica Santillana.-La Sociedad Hidráulica Satillana, como Entidad abastecedora de Madrid, tiene una importancia muy relativa.

El embalse está formado por la denominada presa del Manzanares, con una capacidad de 45 millones de metros cúbicos y está abastecida por el río Manzanares y los Arroyos de Chozas y Samuriel.

Sale el agua por un canal de siete kilómetros de longitud y capacidad de 3 metros cúbicos por segundo hasta llegar a la Central de Navallar, donde se produce un salto de 300 metros de altura, llegando después las aguas a Madrid, donde se distribuyen por medio de una red de 166 kilómetros.

Suministra a Madrid un caudal de unos 9 millones de metros cúbicos anualmente.

\section{A L.CA N T A R I L L A D O}

El alcantarillado de Madrid está formado por unos joo kilómetros de galería, en su mayor parte visitable, y está dividido en: alcantarillado viejo, unos 200 kilómetros, y nuevo, uniss 300.

El alcantarillado viejo se comenzó a construir en tiempo de Carlos III y ocupa la parte más antigua de la ciudad, o sea, principalmente, los Distritos de Centro, Latina, Hospicio, etc.

El alcantarillado nuevo fué empezado a construir par:ialmente en I9I2, mediante un acuerdo con el Estado, por el cua! éste ha abonado el $5^{\circ}$ por ciento del importe total de las obras. El de barrios extremos ha sido sufragado totalmente por el Municipio.

El servicio municipal de Aguas y Alcantarillado se divide pues, en dos secciones: aguas limpias y aguas residuarias.

El servicio de aguas limpias tiene a su cargo la vigilancia, conservación, ampliación y reforma de los viajes antiguọs de agua, con todas sus fuentes públicas; el proyecto y dirección de las obras de establecimiento de tuberias de servicios públicos; bocas de riego, modelo nuevo y sustitución de las de antiguo modelo; conservación de las mismas y el abastecimiento de agua a los edificios municipales; la intervención técnica en el Canal de Isabel II y Sociedad Hidráulica Santillana, con arreglo a los con772 venios aprobados; los almacenes de materiales para obras del Ra- 
mo y los proyectos, estudios de galerías de servicios urbanos y la conservación de las mismas.

La Sección de aguas residuales o sea de alcantarillado, tiene a su cargo los proyectos, estudios y ejecución de obras de alcantarillado nuevo; la inspección y dirección de limpiezas y conservación y reparación de todo el alcantarillado nuevo y viejo; la inspección de las acometidas particulares, con arreglo a las ordenanzas municipales, así como las brigadas de averías urgentes en el subsuelo; la limpieza y conservación de pozos negros, instalación de fosas sépticas, etc., etc.

También lleva esta Sección.las relaciones con la Comp̣añia del Metropolitano y todas las Empresas que tengan construcciones. subterráneas en la vía pública.

Para todos estos servicios, la Jefatura de Aguas y Alcantarillado cuenta con el siguiente personal técnico: Un Ingeniero Jefe, dos Ingenieros encargados, un arquitecto, cinco Ayudantes, Delineantes, portamiras, etc.; y 246 obreros.

Los gastos por personal son aproximadamente de 1.200 .000 pesetas anuales; $y$ por materiales y conservación de redes de aguas. y alcantarillas, de unos 5.000.000 anuales aproximadamente.

Los ingresos que se deducen por utilización de estos servicios son los siguientes:

Por limpieza de pozos negros

Por utilización de evacuatorios

875 pesetas

Por utilización del alcantarillado

27.250

Por utilización de las Casas de baños

2.070 .000

20.000

\section{INSTALACIONES SANITARIAS}

La Jefatura de Instalaciones Sanitarias tiene a su cargo las obras y Servicios Públicos siguientes:

A. Estación Depuradora de làs aguas residuarias o instalaciones complementarias de la misma.

B. Estaciones Depuradoras de las aguas potables municipales.

C. Estación para el tratamiento de las basuras urbanas.

D. Servicios Públicos de Evacuatorios, Baños y Piscinas, y

E. Inspección de todos los servicios particulares relacionados con los anteriormente indicados. 


\section{A) Estación Depuradora}

Quizá sea uno de los mayores problemas sanitarios que $\mathrm{Ma-}$ drid tiene planteados el de la endemia de fiebres tifoideas y otros trastornos de carácter intestinal que atacan anualmente a un gran porcentaje de la población madrileña (en el año I940 ha habido en Madrid cerca de mil casos de fiebre tifoidea y paratificas), y el origen de esta endemia se debe casi exclusivamente a! consumo de verduras y. hortalizas contaminadas, procedentes de toda la región de huertas situada aguas abajo de la capital, y que se riegan con aguas de los ríos Manzanares y Jarama, después de verter en ellos las aguas del Alcantarillado madrileño, según se ha podido comprobar repetidamente por comparación de las curvas de morbilidad y del consumo de dichas verduras.

Los Servicios Técnicos del Municipio madrileño trataron desde hace mucho tiempo de encontrar una solución a este problema, al cual dedicó especial atención el arquitecto don José de Lorite, que propuso en 1925 la construcción de una pequeña Estación Experimental de Ensayo, que fué erigida en la calle de Méndez Alvaro, y que trataba una pequeña cantidad (250 m. ${ }^{8}$ al día) de aguas negras. Construída esta pequeña estación de ensayo, presentó dicho arquitecto, en el año 1927, un primer proyecto de Estación Depuradora para las aguas residuales de Madrid, consistente, en líneas generales, en un tratamiento previo por sedimentación y un tratamiento biológico posterior por el método de lodos activos, que había dado buenos resultados en la citada estación de ensayo. Aunque aprobado por el Excmo. Ayuntamiento el proyecto citado, no salió a concurso su ejecución; y en el año 1930, en vista de los constantes adelantos que la técnica de depuración de aguas iba adquiriendo, se vió la necesidad de redactar un nuevo proyecto que se acoplara a las principales mejoras obtenidas en dicha técnica, especialmente en lo relativo al tratamiento de lodos por digestión.

Este nuevo proyecto fué confeccionado por los señores Lorite y Escario, siendo aprobado por el Ayuntamiento en 1931. Después de informado por la Comisión Central de Sanidad, que hizo algunas observaciones y señaló ciertas normas, fué sacado a concurso y adjudicadas las obras, en diciembre de r93 I, a la Sociedad "Fomento de Obras y Construc iones, S. A." en unión con la casa "Dorr Oliver N. V.", de I.a Haya, especializada para su774 ministro de la maquinaria. 
Comenzadas las obras, que se iniciaron por la construcción del colector general, se procedió a un estudio sistemático de las características de las aguas negras de Madrid, para conocer su comportamiento real desde el punto de vista de su depuración, haciéndose numerosísimos ensayos y análisis, llegándose a resultados que se apartaban bastante de los supuestos en el proyecto aprobado, y mucho también de los análisis aislados que se habían hecho por el Laboratorio y por el Instituto de Higiene. Se hicieron también sondeos en el lugar de emplazamiento de las obras y se vió, además, la necesidad de completar el proyecto, modificando casi todas las instalaciones, ydotarle de aquellas de carácter imprescindible, pero que no se habían incluído en él. Como por otra parte los gastos de explotación de la Estación Depuradora, tal como se habían proyectado, iban a resultar cuantiosísimos, hubo también un imperativo económico para la revisión total del proyecto.

Por estas razones, el ingeniero señor Gutiérrez Pajares hubo de estudiar un nuevo proyecto que modificara totalmente el primitivo, acoplándolo a todas las exigencias que la composición de las aguas, la naturaleza del terreno y la necesidad de reducir los rasțos de explotación imponían.

Este nuevo proyecto, que es el que se está construyendo, preveía la construcción de la Estación total que Madrid ha de necesitar en un futuro próximo, mediante su ejecución en tres etapas.

La primera para el tratamiento de dos tercios del caudal actual de aguas negras; la segunda etapa consistiría en la ampliación para el tratamiento total de todo el caudal actual de aguas negras, y la tercera etapa consistiría en la ampliación para el tratamiento completo del máximo caudal que en el futuro se prevé que pueda desaguar por el colector general.

El Excmo. Ayuntamiento aprobó la ejecución inmediata de la primera etapa con un presupuesto total de 20.500 .000 pesetas, del cual, unos 7.350.000 pesetas corresponden a maquinaria.

La primera ampliación futura tenía un presupuesto de unos 12 millones de pesetas, y la segunda ampliación, un presupuesto de unos 8.300.000 pesetas.

Las obras de la primera etapa, cuya ejecución inmediata fué aprobada, comprende las siguientes unidades:

I. ${ }^{\circ}$ Un aliviadero general para verter al río el agua exceden- $\mathbf{7 7 5}$ 
te en momentos de lluvias torrenciales y evitar la entrada en el colector de una cantidad excesiva de agua.

2. Un colector general que ha de encauzar las aguas a la Estación de Depuración, con una longitud aproximada de kilómetro y medio y capaz para un caudal en tiempo de lluvias de I $5.350 \mathrm{~m} . "$ por segundo.

$3 .^{\circ}$ Una rejilla automática para la detención y separación de todos los elementos gruesos que arrastran las aguas. Los gruesos separados se envían automáticamente a un molino desintegrador que los tritura completamente y los devuelve a las aguas para que puedan ser sometidos a los mismos procesos que el resto de los lodos.

$4 .^{\circ}$ Un aliviadero corto que sirve para regular el caudal que haya de tratarse en la estación Depuradora, enviando el resto directamente al río por medio de un canal cubierto de suficiente capacidad.

$5^{\circ}$ Dos tanques areneros: uno de ellos automático, tipo "Dorr", con aparatos de clarificación y lavado de la arena. F.sta arena, que se recogerá en proporción aproximada de unos $30 \mathrm{~m}$. al día, se utilizará en los campos de desecación de lodos. Para el caso de interrupción del arenero mecánico y como by-pass, se construye otro arenero sencillo con separación manual de la arena, la cual puede ser también lavada en el mismo aparato del arenero "Dorr".

Iina casa de bombas para la elevación de las aguas que hayan de sufrir el tratamiento previo. Estas bombas, de gran capacirlad. funcionarán automáticamente, acoplándose mediante relais eléctricos al caudal que en cada momento exista.

7. Una cámara de grasas para desmulsionar las partes grasientas y aceitosas que arrastran las aguas y que pueden perjudicar el tratamiento biológico posterior. Para ello lleva un aparato oscilante por el cual se inyecta aire que asciende en finas burbujas y produce el efecto desemulsionador.

8. T) (s grandes tanques de sedimentación previa, de 35 metros de lado, en el fondo de los cuales se irán depositando los lodos que son concentrados en un pocillo central, por medio de un mecanismo tipo "Dorr". En los mismos tanques irán metidos los aparatos recogedores de grasas que a cada vuelta del mecanismo los expulsan automáticamente a unos pozos donde se unen con los lo776 dos que salen del fondo de los tanques. 
9. Cámara subterránea para recogida de lodos, en donde van instaladas unas bombas centrífugas especiales que los elevan a los tanques de digestión.

Io. Tanques de digestión para someter los lodos a una fermentación mecánica a fin de reducir grandemente su volumen, de hacerles imputrecibles y de obtener como subproducto el gas que en la digestión de lodos se produce. Estos tanques van provistos de unos aparatos de mezcla de tipo original por los que circula al mismo tiempo agua caliente que sirve para mantener la temperatura de digestión entre 24 a 25 grados, que es la óptima. También van provistos de campanas individuales para recoger los gases.

I I. Campos de desecación. Desde los tanques de digestión pasarán los lodos digeridos, por gravedad, a estos campos de desecación, sobre los que se extenderán por medio de tuberías a fin de desecarlos al aire libre; una vez secos se extraerán de los campos por medio de vías que los atraviesan. Se espera recoger unas roo Tm. diarias, de lodo seco.

Hasta aquí el tratamiento previo.

El tratamiento posterior, biológico, tendrá por objeto la depuración completa de un 80 por Ioo de las aguas sometidas al tratamiento previo (en la actual etapa), y consistirá en un aliviadero para graduar la cantidad de agua sometida al tratamiento biológico, provisto de su canal para el desagüe al río del exceso de agua.

2. Una casa de bombas para elevar las aguas a las unidades del tratamiento subsiguiente.

3. Tanques de aireación. En la actual etapa se construyen dos grandes tanques de aireación de $\mathrm{IO}_{4} \times 40$ metros, en los que se someterán las aguas, en unión de los lodos activos que en los mismos se produzcan, a una fuerte aireación y agitación, mediante aire invectado por placas difusoras y agitación mecánica sinultánea.

4. Tanques de sedimentación final. Los lodos activos se secimentarán en dos grandes tanques de sedimentación final, de 34 metros de diámetro, de gran profundidad, provistos de aparatos "Dorr" para la recogida de los lodos depositados en su fondo.

Estos lodos se enviarán en parte a la entrada de los tạques de aireación para que produzcan sus efectos depuradores, y el exceso se enviará a los tanques de sedimentación previa, para que.777 
sean recogidos juntamente con los lodos frescos y tratados con éstos en los tanques de digestión. Por la coronación de los tanques. de sedimentacin final rebosarán las aguas ya completamente depuradas, de donde pasarán al río o a los canales de riego.

Como complemento de estas instalaciones de depuración, existirán las complementarias siguientes:

Red Eléctrica, que comprenderá una línea de alta tensión para tomar la energía de la U. E. M.; una caseta de transformación para $700 \mathrm{~K}$. V. A., y las redes de distribución. Además comprence toda la instalación de alumbrado de la Estación, que se había proyectado a base de lámparas de vapor de mercurio, que permiten una gran acuidad visual.

Casa de Máquinas, en la cual irán instalados dos motogeneradores de gas, que utilizan el gas obtenido en los tanques de digestión (con una potencia conjunta de unos I.O0O H. P.) unidos a alternadores eléctricos. El calor almacenado en el agua de refrigeración de los motores y en los gases de escape de los mismos se utiliza precisamente para la calefacción de los tanques de digestión, según antes se indica, aprovechándose así por completo el gas utilizado.

Laboratorio, que forma un edificio aislado, suficientemente dotado y cuya importancia es grande en una Estación, de cuya experimentación ha de depender el detalle de sus futuras ampliaciones.

Edificios secundarios, que comprenden tres grupos, de cuatro viviendas para obreros y dos o tres edificios para las oficinas administrativas, viviendas de Encargado y Mecánico Jefe.

Redes completas de aguas y de desagüe.

Red de caminos de servicios.

Cuando se inició el Movimiento Nacional, se habrían ejecutado ya obras por valor de unos nueve millones y medio de pesetas, incluída la maquinaria acopiada, hallándose ya construído el a livi a de r o general, el colector, la rejilla, los areneros, la cámara de grasas, los tanques de sedimentación previa, el pozo de recogida de lodos, las dos casas de bombas, el laboratorio, la caseta de transformación y un grupo de viviendas para obreros, y en construcción un tanque de aireación, uno de sedimentación final y 778 dos tanques de digestión. 
Hecha en agosto de 1939 una valoración de todos los destrozos sufridos en las obras, lo fueron en $902.153,18$ pesetas, sin contar todos los que quedaron a cargo de la contrata. como por ejemplo, madera, encofrados, hierro no recibido, instalaciones auxiliares, hormigoneras, bombas de hormigón, etc., cuyo valor se puede calcular aproximadamente en otro millón de pesetas.

Las obras van, naturalmente, a un ritmo bastante lento, debido a la gran dificultad que existe para la obtención de algunos materiales, como hierro y material eléctrico, y también para el su.. ministro de maquinaria, en especial aquella que necesariamente ha de ser importada por no fabricarse en España.

Ampliaciones futuras.-Como anteriormente se ha dicho, en el proyecto primitivo se preveían ya todas las ampliaciones necesarias para completar la Estación Depuradora, que habrían de servir para la totalidad del futuro caudal de aguas negras. Pero como la primera de dichas ampliaciones suponía un coste que se valuaba en más de 12 millones en I936, y hoy ha de ser mucho mayor, el Ayuntamiento ha aprobado la inclusión en su plan de obras de r940 de una ampliación parcial, para la cual ha dispuesto se consignen 8 millones de pesetas. Esta ampliación parcial, cuyo proyecto de detalle se está redactando, consistirá en el tratamiento previo, intensivo, del caudal total actual de aguas residuales, dejando para el futuro las ampliaciones relativas al tratamiento biológico, en el cual se presentan las mayores dificultades, puesto que la maquinaria de importación se refiere casi exclusivamente a él. Aparte de esta ampliación, el Municipio ha concedido un crédito de 5.600 .000 pesetas para el abono de las obras de reparación y reposición de los destrozos en.época roja, para los de defensa de la Estación y para los aumentos oficiales del 13 por 100 y del 17,5 por roo que fueron concedidos a las Contratas iniciadas con anterioridad a 1936.

Tanto el estudio de los proyectos como el funcionamiento de la Estación, requieren un cúmulo de datos y de investigaciones y análisis previos que no pueden obtenerse sino mediante la cooperación de personal especializado en esta clase de materias. 
B) Estaciones Depuradoras de las aguas potables MUNICIPALES.

El Ayuntamiento de Madrid sólo posee la propiedad de las aguas correspondientes a los llamados antiguos viajes que constituyeron los primitivos abastecimientos de la ciudad, ya que los modernos, como son el Canal de Santillana y especialmente el Canal de Isabel II o del Lozoya, pertenecen respectivamente a empresas particulares o estatales. Los antiguos viajes recogían el agua on minas filtrantes construidas en lugares que en aquel entonces se hallaban bastante alejados de la población, y se conducían por minas sin revestir. A medida que la población fué extendiéndose se acercó a los orígenes de tales viajes rebasándolos en varios casos, por' lo que algunos han ido desapareciendo, conservándose tan sólo los denominados de la Alicubilla, Castellana, Alto Abroñigal y Bajo Abroñigal, cuya aportación diaria no excede mucho de los $3.000 \mathrm{~m}^{3}$. La forma de captación-al poblarse sus orígenes con edificaciones-y la de distribución, hacen muy fácil y posible la contaminación de las aguas, por cuya razón se construyeron en I9I2 tres Estaciones Ozonizadoras, denominadas de Goya, Chamberí y Santa Bárbara, en donde se procede a una depuración de las aguas por medio de ozono producido eléctricamente por el sistema "Otto".

La aplicación de este sistema a las aguas de los viajes no se puede considerar como muy eficiente, por cuanto es muy difícil graduar la dosificación de ozono, y las complejas instalaciones están sujetas a interrupciones constantes, especialmente ahora en que se hallan ya en un estado de bastante vejez, siendo por lo tanto necesario proyectar nuevos sistemas de depuración para estas aguas, los cuales pueden ser a base de cloramina, o bien por el método oligodinámico; pero por la dificultad de obtener en el actual momento aparatos de dosificación de cloro y amoníaco, verdaderamente buenos, será necesario esperar a que se normalice la situación internacional para hacer esta sustitución. Por otra parte, pudiera suceder que las aguas depuradas por cloro (que indudablemente han de tener algún ligero sabor, diferente del actual) no sean del gusto de las personas que hoy consideran las aguas "gordas" de los antiguos viajes como panacea para infini780 nidad de dolencias del aparato digestivo, en cuyo caso no habría 
otra solución que la supresión de los viajes o la utilización de sus aguas para otros menesteres, como, por ejemplo, lavaderos públicos, piscinas, etc.

\section{C) Tratamiento de basuras}

El tratamiento de basuras se efectúa en una moderna estación de fermentación, cuya explotación comenzó en enero de I935, la cual fué construída por una compañía concesionaria bajo la dirección técnica del servicio y con un presupuesto total de siete millones de pesetas.

Esta instalación es técnicamente la mejor de las realizadas hasta la fecha en Europa, pues tiene características que suponen grandes perfeccionamientos sobre sus similares.

Las basuras, descargadas en un gran foso, son acogidas por grúas mecánicas que las depositan sobre tolvas, de donde pasan a una de las tres cintas transportadoras, previa una separación de materiales metálicos, efectuada por electroimanes. A lo largo de estas tres cintas se efectúa la selección por operarias, debidamente uniformadas y dotadas de guantes, de los productos aprovechables, tales como vidrios, trapos, papel, hojas de lata, hueșos y material inerte, cada uno de los cuales son conducidos por sentinas a instalaciones de desinfección, empacados, prensados y llevados, según de que se trate, para su expendición posterior al mercado. Todo esto se efectúa en una sala debidamente ventilada y dotada de cristales azulados para evitar las moscas.

Las basuras así seleccionadas caen en unas elevadoras que mecánicamente las vierten en otras transportadoras que las conducen a las celdas de fermentación.

Estas se hallan en un grandioso edificio que alberga las 400 que en números redondos existen, con capacidad de $25 \mathrm{~m}^{8}$, cada una, contruídas enteramente de hormigón armado y con dispositivos de inyecrión de aire y de purines, así como de evacuación de estos últimos, que permite alcanzar el ciclo fermentativo y la temperatura necesaria durante el mismo y durante la esterilización de los gérmenes patógenos de las basuras.

Estas, después de fermentadas, se descargan y son transportadas a una instalación de criba o bien directamentee a las vagonetas que las conducen a los puntos de empleo. 
La capacidad de tratamiento de esta instalación es de 200 toneladas diarias, ya que se contó con disponer de otra instalación de incineración para igual cantidad, que no llegó a construirse por rescisión del contrato con la entidad adjudicataria.

Los destrozos originados durante la guerra en esta instalación, unidos a dificultades financieras de la empresa, han determinado la imposibilidad de puesta en marcha, hasta el momento presente en que el Ayuntamiento va a proceder a su incautación y a ponerla nuevamente en explotación.

En este ínterin, desde la liberación de Madrid, las basuras han seguido siendo vertidas en el Vertedero del Este, contiguo a la Necrópolis de igual nombre que se aprovecha para rellenar las barrancadas próximas con el fin de destinarlo en su día a zona forestal.

Circunstancialmente se ha aprovechado también un terreno particular situado en la China, contiguo a la Estación de Fermentación, para un mejor aprovechamiento de los carros de tracción animal que aún subsisten por las causas antes indicadas.

En estos momentos el Ayuntamiento se dispone a permitir el aprovechamiento de las basuras de estos vertederos, dada la penuria de fertilizantes existentes en España, mediante el oportuno. concurso en tramitación.

\section{D) Servicios de Piscinas municipales, casas de baños Y EVACUATORIOS.}

Madrid carece de Piscinas municipales, cuya conveniencia se nota cada día más, habiendo sido en diferentes ocasiones demandada su construcción por la opinión pública y por algún diario madrileño.

El Ayuntamiento tiene en estudio unas bases confeccionadas por la Jefatura del Servicio para la concesión de construción y explotación de cuatro Piscinas municipales, cubiertas, enclavadas estratégicamente en las diferentes zonas de la población, a fin de llenar esa sentida necesidad.

Casas de Baños.-Hay construídas actıalmente tres Casas de Baños situadas en la Glorieta de Embajadores, calle de Bravo $\mathrm{Mu}$ 782 rillo y calle de Julián Marín. Las tres poseen instalaciones mo- 
dernas de baños y duchas, y en la última hay además dos pequeñas piscinas, de hombres y mujeres; sin embargo, estas piscinas, por su pequeño tamaño, han tenido muy poco éxito por no prestarse al deporte de la natación. Es indudable que la población de Madrid necesita la construcción de otras Casas de Baños (al menos ctras tres o cuatro), pero su construcción está en cierto modo ligada a la decisión que finalmente adopte el Ayuntamiento en relación con la construcción de piscinas.

Respecto a los servicios que se efectúan en las Casas de Baños, se han prestado en I94I, 40.294 servicios de baños y 50.631 servicios de ducha, casi exclusivamente por las dos Casas de Embajadores y Cuatro Caminos, pues la de Julián Marín o Guindalera fué dedicada durante los años I94I y I942 a la campaña contra el tifus exantemático, en cuya labor prestó durante el año I94I, 320.778 servicios de duchas y 227.105 servicios de desinsectación, además de 73.102 servicios de desinfección de paquetes de ropa, y 8.374 servicios de peluquería.

Evacuatorios.-Existen en Madrid, en servicio, i 7 Evacuatorios, de los cuales 13 son subterránéos y están situados: en la Puerta del Sol (2), Cibeles, Plaza Mayor, Glorieta de Bilbao, Tribunal, Cuatro Caminos, Atocha, Colón, San Gregorio, Lavapiés, Plaza de España y San Millán. Excepto este último, que es sólo para caballeros, tienen todos departamentos de hombres y de mujeres. Los no subterráneos son los cuatro situados en los Parques del Retiro (3) y del Oeste. Casi todos los evacuatorios quedaron en muy mal estado a consecuencia de la pasada guerra de liberación, en especial los de la Plaza de España, Lavapiés y Rosales, habiéndose hecho durante el año I94I una reparación que abarca a todos ellos, excepción hecha del de la Plaza de Colón (Goya). El número de servicios de pago hechos en los evacuatorios durante el año r94I asciende a 333.484.

Ampliaciones. - Es evidente que este servicio de Evacuatorios es de absoluta necesidad para una gran población y que el número existente es pequeño en relación con la gran exten'sión de Madrid y con la concentración de personas que existe en algunos lugares, siendo preciso ampliar sucesivamente su número. En la actualịdad se está terminando el proyecto de ejecución de varios nuevos Evacuatorios' subterráneos, a cuyo fin el Ayuntamiento asignó un crédito de un millón de pesetas en su último plan de obras, extraordinario. 
Explotación de estos servicios.-Cuantas veces se redactaron bases para la explotación del servicio de Casas de Baños y de Evacuatorios, quedaron desiertos los concursos anunciados, pero es de esperar que después de la construcción de los nuevos Evacuatorios que actualmente se proyectan-que deberán estar situados en lugares de notable aglomeración de público, viniendo a sustituir a los antiguos quioscos "Labat"-sea más factible poder obtener proposiciones en los futuros concursos de cxplotación que puedan hacerse y que son necesarios, puesto que esta clase de servicios, en donde se cobran pequeñas cantidades, pueden explotarse en mucho mejores condiciones por Empresas particulares que por el propio Ayuntamiento.

\section{SERVICIO DE INCENDIOS Y SALVAMENTO}

El Servicio contra Incendios está prestado por el Cuerpo de Bomberos, Corporación dé Vigilancia y Seguridad para atender a los socorros de personas y bienes en caso de incendios, hundimientos, inundaciones y demás calamidades públicas. El servicio es permanente y se presta por retenes de guardia, organizados a base de jornadas de veinticuatro horas, haciendo cada individuo tres de estos turnos a la semana.

La dirección del Cuerpo corresponde a un Arquitecto Director, que lo es de todos los servicios.

La Sección activa corresponde al Cuerpo de extinción, con un Arquitecto segundo Jefe, bomberos, conductores y aspirantes bomberos.

Los servicios auxiliares están constituídos por la Inspección médica, con Inspector médico, practicante y ordenanza enfermero; oficina administrativa, con un Jefe administrativo, interventor $\mathrm{y}$ auxiliares taquígrafos-mecanógrafos; un delineante afecto a la Sección técnica; almacén, formado por guanda-almacén, obreros de talleres y ordenanzas de idem; talleres mecánicos a cargo de un Maestro ajustador jefe y obreros mecánicos; Profesor de gimnasia, monitores de ídem, telefonistas y ordenanzas.

Locales. - Existe el de la Dirección, en donde hay un coche de primera salida donde va el Jefe de zona de guardia con 784 los bomberos de dotación. En este local están instalados los des- 
pachos de Jefes, oficina administrativa, estudios técnicos, archivo, clínica y central telefónica.

En la actualidad hay tres parques de servicios por haber sido destruído el cuarto por los efectos de la guerra, y cuyo servicio se halla accidentalmente incorporado al primero. En ellos cstán instalados locales para gimnasia, talleres, cocheras, almacenes, clases de instrucción teórica, cámara de gases, torres de maniobras, secadores y demás dependencias del servicio general, como. dormitorio, comedor, cocina, cuartos de aseo, etc.

Carruajes.-El Cuerpo posee distintos tipos de carruajes. Coches primera salida: con pequeño tanque de agua, bomba de I.500 litros por minuto de rendimiento y toda clase de elementos para salvamentos urgentes, lo mismo en partes altas que en pozos o sótanos. Llevan mangajes surtidores, manguitos de toma, absorbentes, . manguitos de rotura, herramientas, martilios, piros, palas, martillo-azadilla, tronzadores, serruchos. hachas, sierras para metales, elementos para actuación sobre conducciones eléctricas, taburetes, pértiga, aislante, tijeras, guantes y alicates, aparatos respiratorios, filtros de distintos tipos para gases, aparatos aislantes, de respiración autónoma,-pequeño reflector, antorchas, linternas y extintores de mano.

Autobomba.-Que lleva lona de salvamento, bomba acoplamiento de 2.500 litros por minuto de rendimiento y más completa dotación de herramientas, mangaje y mayor número de bomberos de dotación.

Autotanque.-Que lleva depósito de agua de 3.000 a 3.500 litros de capacidad, bomba de 2.500 litros de rendimiento por minuto y elementos para conducción de agua.

Electroventilador, con dínamo accionada por. el motor, que permite instalar' reflectores y bombillas, y también tiene un dispositivo para hacer extracción de humos o inyectar aire fresco en los locales.

Camioneta de apeos, que está dotada con herramientas de carpintería, bridas y maderos para apeos urgentes.

Autos-escalas, con dispositivos de despliegue, tipo telecópico, giro y elevación accionados por el motor del coche.

Moto-bombas, montadas sobre parihuelas, transportables. sobre carrillos remolque, con rendimiento de $\mathrm{I} .000$ litros por minuto y producción de espuma.

Grupos electrógenos de alumbrado y grupos electro-bombas. para desagües.-El equipo personal del bombero está compuesto 
de vestuario, casco, impermeable de cuero, cinto, cuerda, linterna, máscara y filtro para la misma, botas de cuero y goma.

La consignación en presupuesto para personal es de 2.3 I 5 . I 50 pesetas.

Pesetas

Para material, entretenimiento y conservación del material del servicio $\ldots \ldots \ldots \ldots \ldots . \ldots \ldots \ldots \ldots$

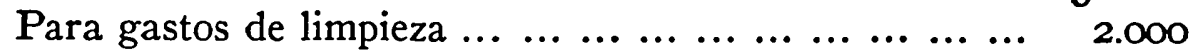

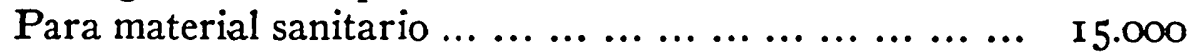

Para gastos de calefacción..................... 9.000

Para camas y prendas de las mismas ... ........... 21.000

Para obras menores y gastos de conservación de edifi-

cios de la Dirección y Parques ... ... ... ... ....... 8.000

Para gastos de entretenimiento, reparación y conser-

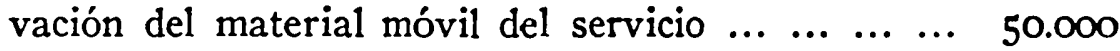

Para vestuario y calzado de personal ... ............ 80.000

Además, existen consignados en el presupuesto extraordinario dos millones de pesetas, con cargo al cual se hacen las adquisiciones más importantes.

La plantilla está compuesta por un Arquitecto, Director del servicio, un Arquitecto segundo Jefe, cuatro Jefes de zona. nueve capataces, tres de ellos aparejadores, Jefes de parques, 289 bomberos, 68 conductores, un Médico, un practicante y un Profesor de gimnasia.

El material lo componen:

Vehículos.-Cinco coches con bomba de $\mathbf{I} .500$ litros de rendimiento por minuto y depósito de agua de 400 litros.

Tres coches con bomba de $\mathbf{1} .500$ litros de rendimiento $y$ 2.200 de depósito.

Un coche con bomba de 1.500 litros, pendiente de terminar.

Tres coches-tanque, con bomba de 3.000 litros de rendimiento por minuto y depósito de 3.000 litros.

Un coche-tanque, de 3.000 litros de rendimiento y 3.500 de depósito.

Dos coches-bomba, de 3.000 litros de rendimiento, sin depósito de agua.

Un coche electro-ventilador.

Dos camionetas para apeos.

Cinco auto-escalas. 
Cuatro motobombas con producción de espuma.

Dos tipos electrógenos de alumbrado.

Cinco grupos electro-bombas.

Mangaje. -245 trozos de lona de $45 \mathrm{~mm}$. de diámetro interior, de 12 a 15 metros aproximadamente.

185 trozos de lona de $70 \mathrm{~mm}$ de diámetro interior y de 12 a 15 metros aproximadamente.

92 trozos de goma y lona, $45 \mathrm{~mm}$. de diámetro interior y de I2 a 15 metros de longitud aproximadamente.

73 trozos de goma y lona, de $70 \mathrm{~mm}$. de diámetro interior y de 12 a 15 metros de longitud aproximadamente.

ro trozos de 20 metros.

66 absorbentes de goma y lona con espiral de alambre en trozos de dos metros.

Aparatos de extinción.-I2 bombitas de mano.

60 cubos de lona.

Io extintores de líquido.

Dos extintores de espuma.

Dos extintores de polvo.

Además, la Sección técnica emite informes en la tramitación municipal de expedientes para licencias de construcción y aperturas de establecimientos industriales y pequeñas industrias, con arreglo a la reglamentación existente en la materia.

(Concluirá.) 